\title{
उMR
}

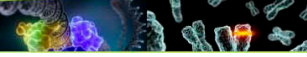

\section{Serum microRNA-135a downregulation as a prognostic marker of non-small cell lung cancer}

\author{
Y.K. Zhang ${ }^{1 *}$, B. Sun ${ }^{2 *}$ and G. Sui ${ }^{3}$ \\ ${ }^{1}$ Department of Thoracic Surgery, Taian City Central Hospital, \\ Taian, Shandong, China \\ ${ }^{2}$ Department of Chest Surgery, \\ First Affiliated Hospital of Dalian Medical University, Dalian, China \\ ${ }^{3}$ Department of Thoracic Surgery, \\ General Hospital of Jinan Military Command, Jinan, Shandong, China \\ *These authors contributed equally to this study. \\ Corresponding author: G. Sui \\ E-mail: suigangl@sina.com
}

Genet. Mol. Res. 15 (3): gmr.15038252

Received December 11, 2015

Accepted March 18, 2016

Published August 12, 2016

DOI http://dx.doi.org/10.4238/gmr.15038252

Copyright $(\subset) 2016$ The Authors. This is an open-access article distributed under the terms of the Creative Commons Attribution ShareAlike (CC BY-SA) 4.0 License

ABSTRACT. Abnormal expression of microRNA-135a (miR-135a) is closely associated with oncogenesis. However, the relationship between serum miR-135a levels and the clinical parameters and prognosis of non-small cell lung cancer (NSCLC) remain unclear. The study aimed to investigate the clinical significance of serum miR-135a expression in patients with NSCLC. miR-135a expression was analyzed by realtime PCR and its correlation with NSCLC was determined by various statistical methods for 104 NSCLC patients and 40 healthy volunteers. The serum miR-135a level was significantly lower in NSCLC patients than in healthy control subjects $(\mathrm{P}<0.01)$, and was closely related to

Genetics and Molecular Research 15 (3): gmr.15038252 
distant metastasis $(\mathrm{P}<0.015)$, lymphatic metastasis $(\mathrm{P}=0.000)$, TNM (tumor node metastasis) stage $(\mathrm{P}=0.001)$, and pathological stage $(\mathrm{P}=$ 0.021 ) of NSCLC. The five year overall survival was significantly lower in patients with low miR-135a expression than that in patients with high serum miR-135a levels $(P=0.010)$. Multivariate analysis showed that serum miR-135a level could be treated as an independent risk factor for NSCLC prognosis $(\mathrm{P}=0.011)$. In conclusion, the serum miR-135a level was downregulated in NSCLC patients, and was associated with poor prognosis. Additionally, it can be used as a biomarker for NSCLC prognosis.

Key words: miR-135a; Serum; Prognosis; Non-small cell lung cancer

\section{INTRODUCTION}

Lung cancer is one of the most common types of cancer, with approximately 1.5 million new cases being reported each year worldwide (Jemal et al., 2011). Despite the advances in the clinical diagnosis and treatment of lung cancer, its prognosis remains poor; this could be attributed to the complicated pathogenesis of the disease. Non-smallcell lung cancer (NSCLC) accounts for more than $80 \%$ of all lung cancer cases (Zhu et al., 2015). NSCLC oncogenesis is a multistep process, and includes genetic mutations and epigenetic changes, among others. Environmental factors, such as the smoking and drinking habits of the patients, and air pollution, also play a major role in lung cancer progression (Hecht, 2012; Dresler, 2013). So far, the molecular mechanism regulating the development and progression of NSCLC remains unclear. Therefore, the identification of specific biomarkers for the early prevention, diagnosis, and treatment of NSCLC is of great significance. The detection of these biomarkers in body fluids, including saliva, plasma, serum, and urine, has many advantages, such as convenient detection, a low amount of trauma, and real-time monitoring.

MicroRNA (miRNA) are small endogenous non-coding RNA composed of 21-25 nucleotides, which often target mRNA via posttranscriptional regulation, or by breaking down the target mRNA. miRNA are widely involved in the regulation of physiological functions, such as proliferation, survival, differentiation, migration, and development, in cells and organisms (Shenoy and Blelloch, 2014). Furthermore, abnormal miRNA expression is associated with the development and progression of several diseases including cancer (Calin and Croce, 2006; Li et al., 2015; Zhang et al., 2015). miRNA may function as an oncogene or a tumor suppressor gene in tumorigenesis (Sana et al., 2012).

Abnormal expression of miR-135a is believed to be associated with oncogenesis. Based on the significant decrease in miR-135a expression in NSCLC tissues and cell lines compared to that in normal control tissues and cells, a previous study theorized that miR-135a suppresses tumor progression in NSCLC (Shi et al., 2015). However, the relationship between serum miR-135a levels and the clinical parameters and prognosis of NSCLC remains to be clarified. Therefore, the aim of this study was to identify the possible correlation between serum miR-135a levels and the clinical significance of NSCLC by real-time PCR.

Genetics and Molecular Research 15 (3): gmr.15038252 


\section{MATERIAL AND METHODS}

\section{Case selection}

A total of 104 NSCLC patients and 40 healthy volunteers were recruited to this study from the Taian City Central Hospital between January 2008 and June 2014. The patients did not receive treatment of any kind, including radiotherapy, chemotherapy, or surgery, before sampling. The NSCLC and control groups were comprised 57 male and 47 female patients (age: 38-82 years) and 19 male and 21 female subjects (age: 26-75 years), respectively. Peripheral blood $(5 \mathrm{~mL})$ was obtained from each subject and allowed to stand for $1 \mathrm{~h}$ at room temperature. The samples were subsequently centrifuged at $1000 \mathrm{~g}$ for $10 \mathrm{~min}$ at $4^{\circ} \mathrm{C}$; the obtained supernatant was centrifuged again at $12,000 \mathrm{~g}$ for $2 \mathrm{~min}$ at $4^{\circ} \mathrm{C}$. All samples were stored at $-80^{\circ} \mathrm{C}$.

This study was approved by the Ethics Committee of the Taian City Central Hospital. Informed consent was obtained from all NSCLC patients and healthy volunteers.

\section{Real-time PCR}

Total RNA was extracted from the blood samples using a standard TRIzol reagent (TaKaRa Bio Inc., Otsu, Shiga, Japan). The RNA samples were reverse transcribed using the PrimeScript RT reagent kit (TaKaRa Bio Inc.) at $37^{\circ} \mathrm{C}$ for $15 \mathrm{~min}$ and $85^{\circ} \mathrm{C}$ for $5 \mathrm{~s}$. The relative cDNA expression level was detected using a standard SYBR Premix DimerEraser kit (TaKaRa Bio Inc.). Real-time PCR was performed on an Applied Biosystems ${ }^{\circledR} 7500$ Fast Realtime PCR system (Applied Biosystems, Foster City, CA, USA). The PCR conditions were set as follows: an initial denaturation at $95^{\circ} \mathrm{C}$ for $4 \mathrm{~min} ; 40$ cycles of denaturation at $95^{\circ} \mathrm{C}$ for $15 \mathrm{~s}$, annealing at $55^{\circ} \mathrm{C}$ for $30 \mathrm{~s}$, and extension at $71^{\circ} \mathrm{C}$ for $34 \mathrm{~s}$. U6 snRNA was used as the internal reference, and the miR-135a expression level was calculated by the $2^{-\Delta \Delta \mathrm{Ct}}$ method. The primers used are listed in Table 1.

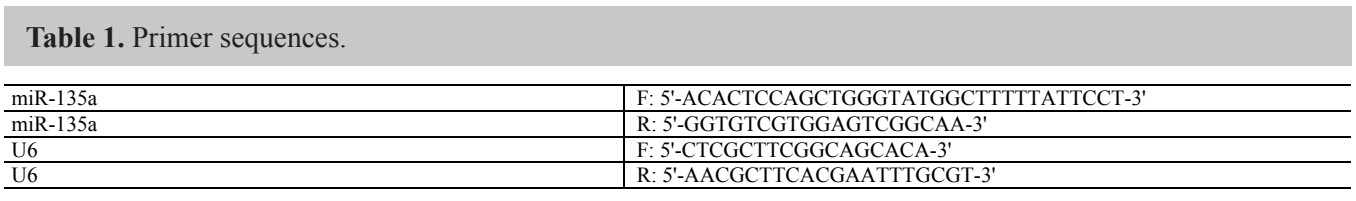

\section{Statistical analysis}

The miR-135 expression was analyzed by the Mann-Whitney U test. The relationship between serum miR-135 levels and the clinical parameters of NSCLC was analyzed by the chi-square test. The relationship between the serum miR-135a level and 5 year overall survival (OS) was evaluated by the Kaplan-Meier method. The independent prognostic factor of NSCLC was determined using the univariate and multivariate proportional hazards models. All data are reported as means \pm standard deviation. All statistical analyses were performed using the SPSS v.22.0 software platform (IBM, Armonk, NY, USA). P values $<0.05$ indicated statistically significant differences. 
Y.K. Zhang et al.

\section{RESULTS}

\section{Serum miR-135a expression in NSCLC patients and healthy controls}

Real-time PCR analysis showed a significant decrease in the serum miR-135a levels in NSCLC patients compared to that in normal control subjects $(\mathrm{P}<0.01)$ (Figure 1).

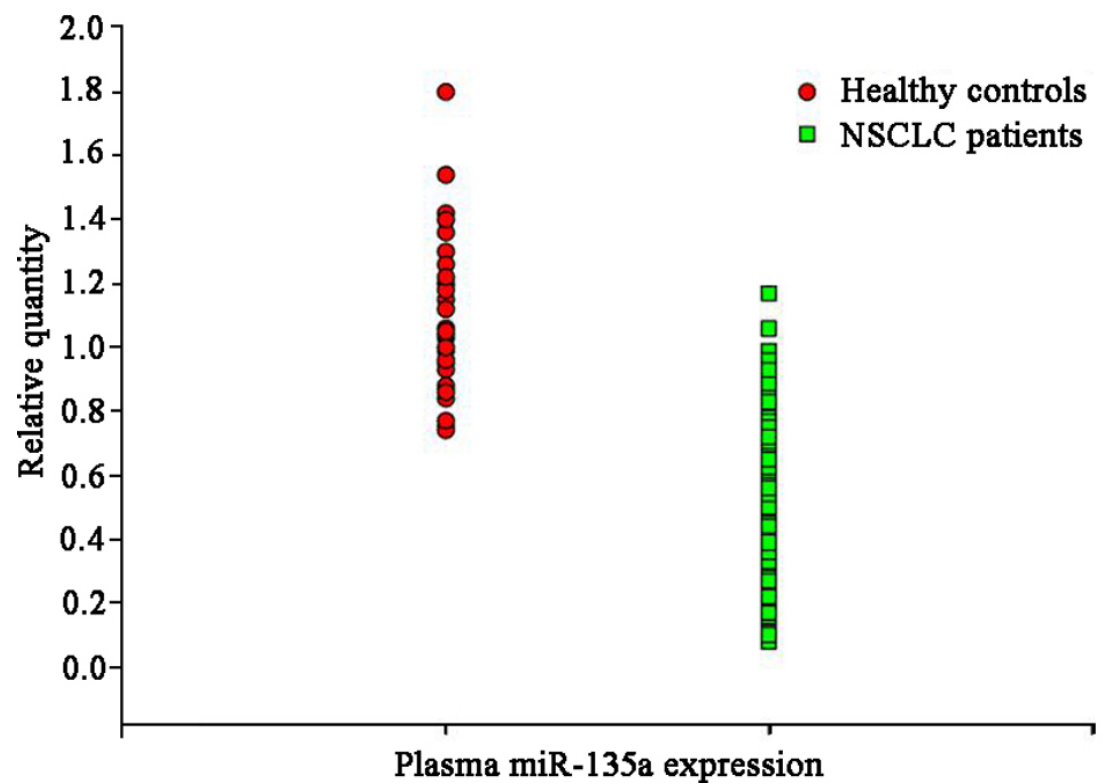

Figure 1. Serum miR-135a expression in non-small cell lung cancer (NSCLC) patients and normal control subjects.

\section{Relationship between serum miR-135a levels and clinical parameters of NSCLC}

The NSCLC patients $(\mathrm{N}=104)$ were further divided into two groups (high and low miR-135a groups) based on the median value of miR-135a (0.57) in the patients, in order to evaluate the relationship between the serum miR-135a level and the clinical parameters of NSCLC. The serum miR-135a level was significantly associated with distant metastasis $(\mathrm{P}<$ $0.015)$, lymphatic metastasis $(\mathrm{P}=0.000)$, TNM stage $(\mathrm{P}=0.001)$, and pathological stage ( $\mathrm{P}$ $=0.021)$ in the NSCLC patients. In contrast, this level was not significantly correlated with the gender $(\mathrm{P}=0.708)$, age $(\mathrm{P}=0.979)$, and family history $(\mathrm{P}=0.543)$ of the patients (Table 2 ). The 5-year OS of patients in the low miR-135a group was significantly lower than that of patients in the high miR-135a group $(\mathrm{P}=0.010)$. Multivariate analysis indicated that miR$135 \mathrm{a}$ in the serum could be an independent risk factor of NSCLC prognosis $(\mathrm{P}=0.011)$.

\section{Survival analysis}

The difference in OS between patients in the high and low miR-135a groups was analyzed by the Kaplan-Meier method. The OS in patients in the high and low miR-135a

Genetics and Molecular Research 15 (3): gmr.15038252 
groups were found to be significantly different (68.62 and $43.4 \%$, respectively; $\mathrm{P}=0.01$ ) (Figure 2).

Table 2. Relationship between serum microRNA-135a level and clinical parameters of non-small cell lung cancer (NSCLC)

\begin{tabular}{|c|c|c|c|c|}
\hline \multirow[t]{2}{*}{ Variable } & \multirow[t]{2}{*}{ Cases (\%) } & \multicolumn{2}{|c|}{ miR-135a (N, \%) } & \multirow[t]{2}{*}{$\mathrm{p}$} \\
\hline & & Low expression & High expression & \\
\hline \multicolumn{5}{|l|}{ Gender } \\
\hline Male & $57(54.81)$ & $30(28.85)$ & $27(25.96)$ & 0.708 \\
\hline Female & $47(45.19)$ & $23(22.11)$ & $24(23.08)$ & \\
\hline \multicolumn{5}{|l|}{ Age } \\
\hline$<60$ & $45(43.27)$ & $23(22.11)$ & $22(21.15)$ & 0.979 \\
\hline$\geq 60$ & $59(56.73)$ & $30(28.85)$ & $29(27.88)$ & \\
\hline \multicolumn{5}{|l|}{ Distant metastasis } \\
\hline No & $89(85.58)$ & $41(39.42)$ & $48(46.15)$ & 0.015 \\
\hline Yes & $15(14.42)$ & $12(11.54)$ & $3(2.88)$ & \\
\hline \multicolumn{5}{|l|}{ Lymphatic metastasis } \\
\hline No & $72(69.23)$ & $28(26.92)$ & $44(61.11)$ & 0.000 \\
\hline Yes & $32(30.77)$ & $25(24.04)$ & $7(6.73)$ & \\
\hline \multicolumn{5}{|l|}{ TNM stage } \\
\hline $\mathrm{T} 1, \mathrm{~T} 2$ & $61(58.65)$ & $23(22.12)$ & $38(36.54)$ & 0.001 \\
\hline T3, T4 & $43(41.35)$ & $30(28.85)$ & $13(12.50)$ & \\
\hline \multicolumn{5}{|l|}{ Pathological stage } \\
\hline Highly-moderately differentiated & $82(78.85)$ & $37(35.58)$ & $45(43.27)$ & 0.021 \\
\hline Poorly differentiated & $22(21.15)$ & $16(15.38)$ & $6(5.77)$ & \\
\hline \multicolumn{5}{|l|}{ Family history of cancer } \\
\hline No & $86(82.69)$ & $45(43.27)$ & $41(39.42)$ & 0.543 \\
\hline Yes & $18(17.31)$ & $8(7.69)$ & $10(9.62)$ & \\
\hline
\end{tabular}

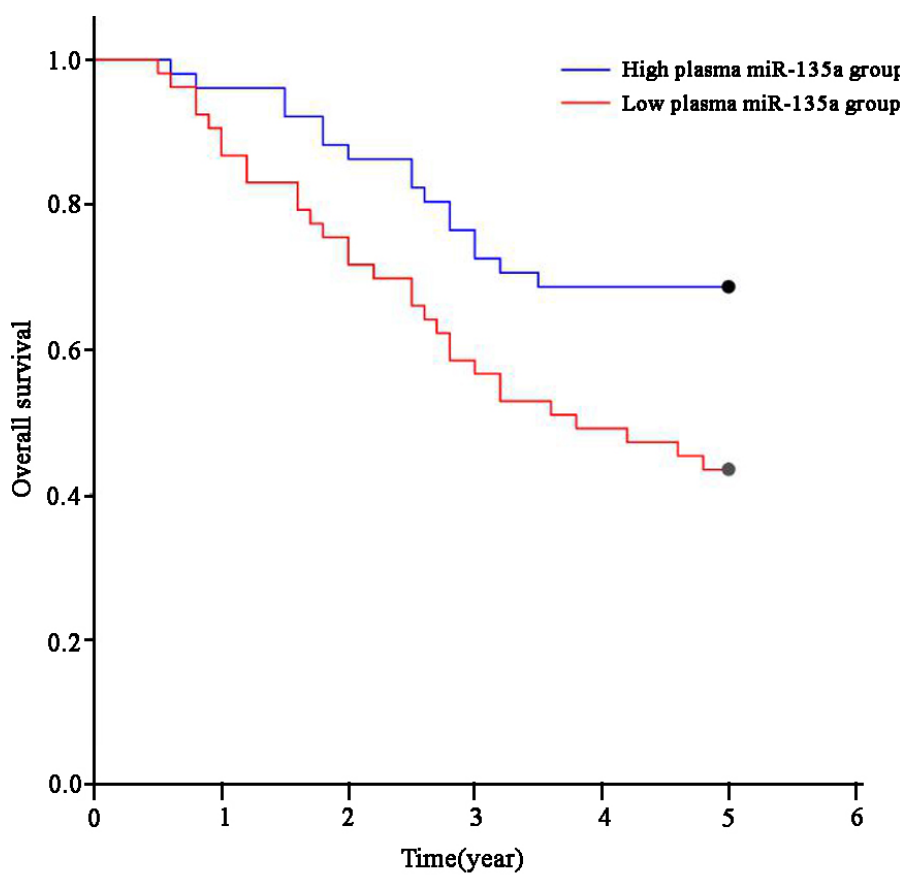

Figure 2. Relationship between serum miR-135a expression and overall survival.

Genetics and Molecular Research 15 (3): gmr.15038252 


\section{Correlation between clinical factors and NSCLC prognosis}

Univariate analysis indicated a significant correlation between distant metastasis $(\mathrm{P}=$ $0.018)$, lymphatic metastasis $(\mathrm{P}=0.003)$, TNM stage $(\mathrm{P}=0.035)$, and serum miR-135a level $(\mathrm{P}=0.006)$ and NSCLC prognosis (Table 3$)$.

Table 3. Univariate analysis of the factors affecting non-small cell lung cancer (NSCLC) prognosis.

\begin{tabular}{l|cc}
\hline Factor & HR $(95 \% \mathrm{CI})$ & $\mathrm{P}$ \\
\hline Gender (male $v s$ female) & $1.282(0.368-1.865)$ & 0.736 \\
\hline Age $(\geq 60 v s<60)$ & $1.435(0.247-2.568)$ & 0.438 \\
\hline Distant metastasis (yes $v s$ no) & $3.140(1.617-7.352)$ & 0.018 \\
\hline Lymphatic metastasis (yes $v s$ no) & $5.875(2.684-12.380)$ & 0.003 \\
\hline TNM stage (T3, T4 $v s$ T1, T2) & $2.893(1.821-6.281)$ & 0.035 \\
\hline Pathological stage (poor $v$ high-moderate differentiation) & $2.059(0.912-4.028)$ & 0.680 \\
\hline Family history (yes $v s$ no) & $1.307(0.450-2.135)$ & 0.006 \\
\hline Serum miR-135a (low $v s$ high) & $3.872(2.261-9.621)$ & \\
\hline
\end{tabular}

HR, hazard ratio; CI, confidence interval.

In contrast, multivariate analysis revealed that lymphatic metastasis $(\mathrm{P}=0.002), \mathrm{TNM}$ stage $(\mathrm{P}=0.038)$, and the serum miR-135a level $(\mathrm{P}=0.011)$ could be treated as independent risk factors for NSCLC prognosis (Table 4).

Table 4. Multivariate analysis of the factors affecting non-small cell lung cancer (NSCLC) prognosis.

\begin{tabular}{l|c|c}
\hline Factor & HR $(95 \% \mathrm{CI})$ & P \\
\hline Distant metastasis (yes $v s$ no) & $2.358(0.87-5.360)$ & 0.059 \\
\hline Lymphatic metastasis (yes $v s$ no) & $6.351(3.084-14.156)$ & 0.002 \\
\hline TNM stage (T3,T4 $v s$ T1, T2) & $2.920(1.482-7.628)$ & 0.038 \\
\hline Serum miR-135a (low $v s$ high) & $3.527(1.872-8.983)$ & 0.011 \\
\hline
\end{tabular}

HR, Hazard ratio; CI, confidence interval.

\section{DISCUSSION}

NSCLC is the leading cause of cancer-related deaths worldwide. Early diagnosis of NSCLC plays a vital role in improving patient prognosis (DeSantis et al., 2014; Siegel et al., 2014). NSCLC does not present specific symptoms or biomarkers during the early stage; therefore, most cases are diagnosed during the late stage of the disease. However, the prognosis of advanced NSCLC is poor. Currently, surgical resection is the only method that has shown potential in the effective treatment of malignant tumor; however, recurrence occurs in $65 \%$ of the patients with NSCLC within two years after surgery, eventually dying as a result of metastasized tumor (Devesa et al., 1995; Donnem et al., 2007). Therefore, the identification of biomarkers that are expressed during the early stages of NSCLC is very important to improve the effect of therapy, as well as the disease prognosis.

Abnormal expression of miRNA is believed to be associated with oncogenesis; therefore, early diagnosis and treatment of NSCLC could be achieved by detecting the miRNA levels in body fluids (saliva, blood, and urine) or tissues (Hata and Lieberman, 2015; Lan et al., 2015). Recent studies have reported a significant association between miRNA expression

Genetics and Molecular Research 15 (3): gmr.15038252 
and the development, growth, invasion, and metastatic process of NSCLC. Cui et al. (2015) recently reported that miR-224 was significantly overexpressed in NSCLC tissues; miR-224 overexpression has been shown to promote proliferation, migration, and invasion in NSCLC cell lines. Moreover, miR-224 was found to promote NSCLC progression by inhibiting the expression of TNFAIP1 and SMAD4, indicating that miR-224 could be a potential target for NSCLC treatment. In contrast, Chen et al. (2015) reported a marked reduction in the expression of miR-203 in NSCLC tissues, compared to that in adjacent tissues; additionally, miR-203 overexpression was found to effectively restrain cancer cell proliferation and invasion in vitro, implying the tumor suppressing role of miR-203 in NSCLC oncogenesis Therefore, miRNA may promote or inhibit NSCLC oncogenesis, with the specific effect possibly being correlated with the tumor microenvironment and downstream targets.

In this study, we first determined that NSCLC patients expressed significantly lower serum miR-135a levels compared to healthy controls. Additionally, we identified an association between the serum miR-135a levels and distant metastasis, lymphatic metastasis, TNM stage, and pathological stage of NSCLC. Moreover, the OS of NSCLC patients with low serum miR-135a levels was worse than that of patients with high miR135a levels. Multivariate analysis also showed that serum miR-135a expression was an independent prognostic factor of NSCLC. These results suggested that miR-135a played a tumor-suppressing role in NSCLC, which was similar to the conclusions drawn by Shi et al. (2015), who reported a significantly lower miR-135a level in NSCLC tissues and cell lines compared to that in normal control in vitro. Moreover, miR-135a was reported to suppress NSCLC migration and invasion by acting on $K L F-8$, while the expression of the epithelialmesenchymal transition marker E-cadherin and vimentin were found to be correlated with miR-135a regulation. These results indicated the tumor suppressive role of miR-135a and its correlation with tumor metastasis (Shi et al., 2015). Additionally, Zhou et al. (2013) reported a close association between miR-135a/b expression and cisplatin resistance in a lung cancer cell line (miR-135a/b overexpression was shown to effectively increase the sensitivity of cells to cisplatin). This suggested that the regulation of miR-135a expression could lead to an increased chemotherapeutic effect, in addition to inhibiting NSCLC progression. However, other studies have reported that miR-135a overexpression could be related to paclitaxel resistance (Holleman et al., 2011), indicating the complexity of the regulatory effect of miR-135a on NSCLC drug resistance, as well as its correlation with the type of chemotherapeutic drug. Cheng et al. (2013) reported a close association between polymorphisms in the $C D 133$ gene, a miR-135a/b target, and lung cancer susceptibility and survival; this indicated that miR-135a/b could possibly be correlated with lung cancer occurrence and development.

Recent studies have also shown that miR-135a plays different roles in different tumors: as a tumor suppressor gene in gallbladder carcinoma (Zhou et al., 2014) or as an oncogene in colorectal cancer cells, promoting colorectal cancer cell growth and invasion (Zhou et al., 2012). This contrasting effect of miR-135a in different tumors indicated that its biological function is related to the specific cancer type and microenvironment. Moreover, miR-135a is implied to target multiple genes, thereby regulating a complex network.

To sum up, our investigation revealed a decrease in the serum miR-135a levels in NSCLC patients, and its correlation with the poor prognosis of the disease. Therefore, we concluded that serum miR-135a could be used as a biomarker for NSCLC prognosis.

Genetics and Molecular Research 15 (3): gmr.15038252 


\section{Conflicts of interest}

The authors declare no conflict of interest.

\section{ACKNOWLEDGMENTS}

The authors would like to thank the anonymous reviewers of this manuscript for their valuable comments and suggestions.

\section{REFERENCES}

Calin GA and Croce CM (2006). MicroRNA signatures in human cancers. Nat. Rev. Cancer 6: 857-866. http://dx.doi. org/10.1038/nrc1997

Chen T, Xu C, Chen J, Ding C, et al. (2015). MicroRNA-203 inhibits cellular proliferation and invasion by targeting Bmi1 in non-small cell lung cancer. Oncol. Lett. 9: 2639-2646.

Cheng M, Yang L, Yang R, Yang X, et al. (2013). A microRNA-135a/b binding polymorphism in CD133 confers decreased risk and favorable prognosis of lung cancer in Chinese by reducing CD133 expression. Carcinogenesis 34: 2292-2299. http://dx.doi.org/10.1093/carcin/bgt181

Cui R, Meng W, Sun HL, Kim T, et al. (2015). MicroRNA-224 promotes tumor progression in nonsmall cell lung cancer. Proc. Natl. Acad. Sci. USA 112: E4288-E4297. http://dx.doi.org/10.1073/pnas.1502068112

DeSantis CE, Lin CC, Mariotto AB, Siegel RL, et al. (2014). Cancer treatment and survivorship statistics, 2014. CA Cancer J. Clin. 64: 252-271. http://dx.doi.org/10.3322/caac.21235

Devesa SS, Blot WJ, Stone BJ, Miller BA, et al. (1995). Recent cancer trends in the United States. J. Natl. Cancer Inst. 87: 175-182. http://dx.doi.org/10.1093/jnci/87.3.175

Donnem T, Al-Saad S, Al-Shibli K, Delghandi MP, et al. (2007). Inverse prognostic impact of angiogenic marker expression in tumor cells versus stromal cells in non small cell lung cancer. Clin. Cancer Res. 13: 6649-6657. http:// dx.doi.org/10.1158/1078-0432.CCR-07-0414

Dresler C (2013). The changing epidemic of lung cancer and occupational and environmental risk factors. Thorac. Surg. Clin. 23: 113-122. http://dx.doi.org/10.1016/j.thorsurg.2013.01.015

Hata A and Lieberman J (2015). Dysregulation of microRNA biogenesis and gene silencing in cancer. Sci. Signal. 8: re3. http://dx.doi.org/10.1126/scisignal.2005825

Hecht SS (2012). Lung carcinogenesis by tobacco smoke. Int. J. Cancer 131: 2724-2732. http://dx.doi.org/10.1002/ ijc. 27816

Holleman A, Chung I, Olsen RR, Kwak B, et al. (2011). miR-135a contributes to paclitaxel resistance in tumor cells both in vitro and in vivo. Oncogene 30: 4386-4398. http://dx.doi.org/10.1038/onc.2011.148

Jemal A, Bray F, Center MM, Ferlay J, et al. (2011). Global cancer statistics. CA Cancer J. Clin. 61: 69-90. http://dx.doi. org/10.3322/caac.20107

Lan H, Lu H, Wang X and Jin H (2015). MicroRNAs as potential biomarkers in cancer: opportunities and challenges. BioMed Res. Int. 2015: 125094. http://dx.doi.org/10.1155/2015/125094

Li BS, Liu H and Yang WL (2015). Reduced miRNA-218 expression in pancreatic cancer patients as a predictor of poor prognosis. Genet. Mol. Res. 14: 16372-16378. http://dx.doi.org/10.4238/2015.December.9.5

Sana J, Faltejskova P, Svoboda M and Slaby O (2012). Novel classes of non-coding RNAs and cancer. J. Transl. Med. 10: 103. http://dx.doi.org/10.1186/1479-5876-10-103

Shenoy A and Blelloch RH (2014). Regulation of microRNA function in somatic stem cell proliferation and differentiation. Nat. Rev. Mol. Cell Biol. 15: 565-576. http://dx.doi.org/10.1038/nrm3854

Shi H, Ji Y, Zhang D, Liu Y, et al. (2015). MiR-135a inhibits migration and invasion and regulates EMT-related marker genes by targeting KLF8 in lung cancer cells. Biochem. Biophys. Res. Commun. 465: 125-130. http://dx.doi. org/10.1016/j.bbrc.2015.07.145

Siegel R, Ma J, Zou Z and Jemal A (2014). Cancer statistics, 2014. CA Cancer J. Clin. 64: 9-29. http://dx.doi.org/10.3322/ caac. 21208

Zhang M, Zhao LJ, Liang WQ and Mao ZP (2015). Identification of microRNAs as diagnostic biomarkers in screening of head and neck cancer: a meta-analysis. Genet. Mol. Res. 14: 16562-16576. http://dx.doi.org/10.4238/2015. December.11.3

Genetics and Molecular Research 15 (3): gmr.15038252 
Zhou H, Guo W, Zhao Y, Wang Y, et al. (2014). MicroRNA-135a acts as a putative tumor suppressor by directly targeting very low density lipoprotein receptor in human gallbladder cancer. Cancer Sci. 105: 956-965. http://dx.doi. org/10.1111/cas. 12463

Zhou L, Qiu T, Xu J, Wang T, et al. (2013). miR-135a/b modulate cisplatin resistance of human lung cancer cell line by targeting MCL1. Pathol. Oncol. Res. 19: 677-683. http://dx.doi.org/10.1007/s12253-013-9630-4

Zhou W, Li X, Liu F, Xiao Z, et al. (2012). MiR-135a promotes growth and invasion of colorectal cancer via metastasis suppressor 1 in vitro. Acta Biochim. Biophys. Sin. (Shanghai) 44: 838-846. http://dx.doi.org/10.1093/abbs/gms071

Zhu D, Chen H, Yang X, Chen W, et al. (2015). miR-32 functions as a tumor suppressor and directly targets SOX9 in human non-small cell lung cancer. Onco Targets Ther. 8: 1773-1783. http://dx.doi.org/10.2147/OTT.S72457

Genetics and Molecular Research 15 (3): gmr.15038252 